\title{
VIRTUAL REALITY ART AND IMMERSIVE EXPERIMENTAL TYPOGRAPHY
}

\author{
Banu İnanç UYAN DUR \\ Işık Üniversitesi, Türkiye \\ inanc.uyan@isikun.edu.tr \\ https://orcid.org/0000-0003-0259-1716
} Medya Elektronik Dergisi, 5 (3), 219-233

\begin{abstract}
As an emerging technology, Virtual Reality (VR) is perceived as a platform with the potential to change the artwork generation methods and consumption paradigms The immersion, presence and interaction features of VR provides for art unique opportunities to find new forms of expression. The potential of VR in the artistic context will be revealed more clearly as researches in this area increase. The way art uses VR, how it interprets it, and the change VR will cause in art will expand the perspective for both. It is seen that in most of the researches on the relationship between VR and art, this relationship is considered in a general context. Very few researches has been done on the use of writing for artistic purposes in VR and a limited number of practical studies have been produced. From this point of view, in this article, the relationship between experimental typography and VR art is examined with examples. The most effective use of writing in both a linguistic context and as a visual expression has been within the scope of conceptual art and this has brought new discourses and perspectives to the art. In this regards, the inclusion of VR in the combination of writing and art may provide completely different results in conceptual and intellectual contexts. The intersection of writing, art and VR has a rich potential for different perspectives and new patterns. In this paper, the use of writing as the main narrative element in VR Artworks has been discussed as an experimental typography study. Experimental typography is a practice based on exploration and interpretation, seeking new forms of visual expression apart from traditional patterns. VR Artworks based on experimental typography may reveal various contents that explore the role of language for art as structured images in virtual environment. Within this article, three VR Artworks based on the experimental typography are examined and it has seen that they all presented different visual solutions than the clean, meticulous 3D visualization approach used in most VR applications. In this context, it has been suggested that the use of experimental typography in VR Art can expand the narrative language of VR.
\end{abstract}

Keywords: Virtual Reality Art, Experimental Typography, Immersive Typography

\section{SANAL GERÇEKLİK SANATI VE SÜRÜKLEYICİ DENEYSEL TIPOGRAFI}

\section{ÖZ}

Gelişmekte olan bir teknoloji olarak Sanal Gerçeklik (SG), sanat üretimi ve tüketimi paradigmalarını değiştirme potansiyeline sahip bir platform olarak görülmektedir. SG’nin daldırma, varlık ve etkileşim özellikleri yeni ifade biçimleri bulma konusunda sanata benzersiz olanaklar sunmaktadır. SG'nin sanatsal bağlamda potansiyeli bu alanda yapılan uygulamalı çalışmalar ve araştırmalar arttıkça daha net ortaya konacaktır. Sanatın SG'yi kullanış biçimi, onu nasıl yorumladığı ve SG'nin sanatta yaratacağı değişim her iki alanda da perspektifi genişletecektir. Bugüne kadar SG ve sanat ilişkisi üzerine yapılan araştırmaların çoğunda bu ilişkinin genel bağlamda ele alındığı görülmüştür. Yazının SG'de sanatsal 
amaçla kullanımını üzerine çok az araştırma yapılmış ve sınırlı sayıda uygulama çalışması üretilmiştir. Buradan hareketle bu makalede SG'de sanatsal bağlamda yazının kullanımını araştırılmıştır. Yazının gerek dilbilimsel gerekse görsel ifade biçimi olarak en etkin kullanımı, kavramsal sanat kapsamında olmuş ve bu sanata yeni söylemler ve bakış açıları kazandırmıştır. Bu bakımdan, yazı ve sanat birlikteliğine SG'nin de dahil olması, kavramsal ve düşünsel bağlamda ortaya bambaşka sonuçlar çıkarabilir. Yazı, sanat ve SG'nin kesişim noktasının farklı perspektifler yakalama ve yeni örüntüler keşfetme konusunda yüksek bir potansiyeli vardır. Bu makalede SG sanat projelerinde ana anlatı ögesi olarak yazının kullanımı deneysel bir tipografi çalışması olarak ele alınmıştır. Deneysel tipografi, geleneksel kalıpların dışında, keşfe ve yoruma dayalı, yeni görsel ifade biçimleri aramaya yönelik bir pratiktir. Deneysel tipografiye dayalı SG sanat çalışmaları yapılandırılmış imgeler olarak dilin sanattaki rolünü sanal ortam içinde keşfeden farklı içerikler ortaya koyabilir. Bu makale kapsamında deneysel tipografiye dayalı üç SG sanatı çalışması incelenmiş ve çoğu SG uygulamasında kullanılan temiz, özenli 3D görselleştirme yaklaşımdan daha farklı görsel çözümler ortaya koydukları görülmüştür. $\mathrm{Bu}$ bağlamda SG sanatında deneysel tipografi kullanımının SG'nin anlatım dilini genişletebileceği öne sürülmüştür.

Anahtar Kelimeler: Sanal Gerçeklik Sanatı, Deneysel Tipografi, Sürükleyici Tipografi

\section{INTRODUCTION}

Today, the decrease in the production cost of virtual reality technologies and the introduction of devices for individual use of VR have increased the interest in VR. While R\&D and use of virtual reality was limited to academic institutions, research centers and military before, it became commonly known and became a trend as of 1990's. However, this trend did not last long, and a number of initiatives failed on the way.

Many studies state that stereoscopic devices developed in the 1950s and 1960s were pioneering studies of VR technologies. Morton Heilig prototyped his idea of multi-sensory theater in 1962, which he explained in his article The Cinema of the Future in 1955. This is considered a milestone in terms of VR. This device was called Sensorama. The purpose of this device was to simulate the experience of driving a motorcycle in a city with a stereoscopic color display, stereo-sound system, vibrating seat, fan and scent system. The next step in terms of important discoveries was taken by Ivan Sutherland, also known as the pioneer of computer graphics. Another milestone in the history of VR was when Ivan Sutherland developed the first Head Mounted Display (HDM) with head tracking feature in 1968. "The helmet had two mini CRT displays that projected images directly into the user's eyes and you could track the head movements through a mechanical and ultrasonic interface" (Gobira and Mozelli, 2018: 3). After Sutherland's HDM, studies on VR were carried out by military and scientific circles. The development of VR technologies continued with the following: VCASS (Visually Coupled Airborne Systems Simulator) developed by Thomas Furness of US Air Force's Armstrong Medical Research Laboratories in 1982, VIVED (Virtual Visual Environment Display), developed in 1984 by Dr. Mike McGreevy and Jim Humphries of NASA Ames, Dr. Scott Fisher's VIEW Project (Virtual Interactive Environment Workstation) and the Virtual Wind Tunnel, developed at NASA Ames Research Center in the early 1990s. The first VR devices sold on the market, DataGlove (1985) and Eyephone HMD (1988), were manufactured by the VPL company. The CAVE VR system was developed in 1992 with the features enable stereoscopic images to be projected on the wall, which provided a better image quality. As an alternative to using HDM, for CAVE, the user wore LCD shutter glasses. While all these intensive R\&D activities were continuing, computer scientist Jaron Lanier coined the term virtual reality in 1987.

In the 1990s, virtual reality got the public's attention and became hugely popular. But before the end of 1990s, this interest declined within a short period of time and VR ceased to be a center of attention. This situation is attributed to the rapid spread of personal computers and internet access in the 1990s. The center of attention of the industry, researchers and the public shifted towards the Internet. On the other hand, high cost, public expectations and technological limitations of that period can also be listed as important factors as well. It can be seen that, in recent years, VR have had a rapid upward trend. Many variables can be mentioned in terms of this second upwards trend of VR. Particularly, Oculus Rift DK 1, which was initiated in 2012 with the support of Kickstarter and launched in 2013, had a very important 
role. VR was once again the center of attention, especially with Facebook's acquisition of Oculus in 2014. A more advanced version, Oculus Rift, was released in 2016. Also in 2016, HTC Vive, PlayStation VR, Samsung Gear VR, and Google Daydream were launched as well. "Both the technical quality and the availability of VR devices were considerably improved in the past decade with the exponentially growing investment in the development and commercialization of these technologies by prominent companies" (Raz, 2019: 1000).

Having experienced its second trend after the 1990s, VR systems were now low-cost, mobile and practical. These features allowed VR to reach a wider audience. Today, interest in VR is increasing in almost every field such as gaming, cinema, education, health, art, advertising, tourism, industry; and opportunities provided by VR are being discovered. With the same speed, VR content becomes increasingly diverse each day. Content diversity can be exemplified with developments such as singleplayer and multiplayer VR games, 360-degree films, documentaries, narratives, meditation apps, simulations, sports apps, educational apps, events, conferences, and collaboration platforms where meetings can be held. Apps for drawing, painting, animation, modeling can be listed as new expression tools for artists and designers.

VR is not only an emerging technology, but also a new communication system. According to Biocca and Levy (1995:16) "VR is the just the forward edge of general evolution of present communication interfaces like tv, computes and the telephone toward the emerge of metamedium". New communication tools have always been the factors affecting art and design. VR performs the communication process using interaction, visualization and other sensory stimulis. In this respect, the most important effect of VR on art and design is that it is an immersive and multi-sensory experience. The innovations that VR will bring to the forms of artistic expression will expand with the increase of researches. Various researches and VR Art experiences have been made for the artistic use of VR. However, the interaction of VR and art is a dynamic and diverse field that requires more research and practice. For example, very few researches has been done on the use of writing for artistic purposes in VR and a limited number of practical studies have been produced. From this point of view, in this article, the relationship between experimental typography and VR art is examined with examples.

\section{VIRTUAL REALITY}

Virtual reality is a computer-generated 3D virtual environment that can interact and manipulate with the user in real time. Head, hand and body tracking systems are used by the user to be able to experience this virtual environment with one or more senses, move and interact. Gigante (1993: 3) defines virtual reality as "The illusion of participation in a synthetic environment rather than external observation of such an environment. VR relies on a three-dimensional, stereoscopic head-tracker displays, hand/body tracking and binaural sound. VR is an immersive, multi-sensory experience". Bryson (2013) uses the term effect instead of illusion and argues that this is not an illusion but a cognitive effect: "Virtual Reality is the use of computer technology to create the effect of an interactive three-dimensional world in which the objects have a sense of spatial presence" (Bryson, 2013: 4). VR offers an interactive and immersive experience through a simulated 3D environment. "Virtual reality refers to immersive, interactive, multi-sensory, viewer-centered, three dimensional computer generated environments and the combination of technologies required to build these environments" (Cruz-Neira, 1993).

The ultimate goal of virtual reality is to make the user feel the sense of being there while experiencing the virtual environment, even if they are physically located elsewhere. Being there defines the concept of presence, which is one of the key features of virtual reality. Another key concept of VR is immersion. Although the concepts of presence and immersion are related with one another, these two concepts do not have the same meaning. Immersion is about the technological capability of virtual reality systems. According to Slater et al. (1996) immersion is "an objective description of what any particular system does provide". In other words, the vividness of the virtual environment provided by the VR system determines the level of immersion. VR is a viewer-centered experience; therefore, it requires the user to have a virtual body in a virtual environment. The factors that has an effect on the immersion level can be listed as matching of the user's real body with virtual body movements, the user's interaction with the virtual environment, multi-sensory features providing a reality effect on the user's consciousness and so 
forth. "Immersion consists in the possibility to experience a virtual environment from a first-person perspective and in the sensorial isolation from the real world, as well as in the technological degree of sophistication" (Chirico, 2018: 2).

An attempt to explain the concept of immersion only in terms of technological capability may not be enough to fully understand the concept. The quality of VR content (games, applications or 360 videos) is also very effective in creating an immersive virtual environment for the user. In addition, although it is a concept related to the technological capability of virtual reality systems, there are also claims suggesting that immersion is a subjective psychological experience (McMahan, 2003; Mütterlein, 2018). The concept of presence is mostly associated with subjectivity. The degrees of presence are related to the level of immersion, and they vary from person to person. The fact that users really feel there when they are in the virtual environment can be explained by the concept of presence. "Presence is a state of consciousness, the (psychological) sense of being in the virtual environment, and corresponding modes of behavior" (Slater et al, 1996: 165). VR attempts to create the same effect that the sense of being there provides to people when they perceive their physical reality with their senses, through simulating this feeling. For users to experience the effect of reality is related to experiencing a sense of presence. "This reality may be attempting to replicate our reality, or it may be an abstract and completely synthetic reality, in either case the end goal is to create the illusion that the viewer is inhabiting this simulated space" (Kelley and Tornatzky, 2019: 2). Presence is correlated with immersion and they have a positive correlation. But immersion is not the only factor affecting presence. Studies prove that VR content that stimulates emotions also increases presence. Studies show that there is a correlation between presence and emotion (Baños et al., 2004; Freeman et al., 2005; Diemer et al., 2015; Visch et al., 2010). This situation also proves the significance of the quality of the content (games, films, educational apps, etc.) provided by virtual reality. The VR content should be able to create an emotional effect on the users and provide immersive experiences.

\section{VIRTUAL REALITY ART}

The use of VR as an art medium goes back to the 1990s. Due to the fact that VR equipment was an expensive technology and there was no widespread sales network, a limited number of VR Artworks were made in those years. Brenda Laurel and Rachel Strickland's Placeholder (1992), Char Davies's Osmose (1995), Maurice Benayoun's The Tunnel Under the Atlantic (1995), Char Davies's Ephémère (1998) and Blast Theory's Desert Rain (1999) used VR as an art medium; and these artworks can be listed as pioneering first-generation VR Artworks, which are considered as one of the best examples even today. Interactive installations of VIDEOPLACE by Myron Krueger (1974) and The Legible City by Jeffrey Shaw (1989), which inspired VR artworks, are revolutionary studies for full-body interaction in a computer-generated environment. After the launch of Oculus Rift (2016), which was the more advanced version of Oculus Rift DK 1 (2013), the use of VR as an art medium increased.

Immersion, presence, and interaction features of virtual reality provide unique opportunities for artists and designers. These unique opportunities support creativity and inspire artists to explore conceptually new perspectives and methods. In this sense, it can be said that VR has more potential to expand the perception, examination and interpretation of artists compared to all other mediums. The use of VR by the artists should be evaluated from different aspects. First of all, VR has a unique potential for artists who seek providing new dimensions as well as developing different languages and striking discourses to their artworks. What is more important is that the key group that will be able to discuss VR in an intellectual context are the artists. Artists who consider virtual reality in the context of being, reality, presence, perception, body, medium, and so forth (should) look beyond technology. The potential of VR as an art medium was also emphasized by predecessors of VR. According to Brenda Laurel (1995: 90), as artists discover the expression potential of VR, VR technology and tools will evolve accordingly "Artists, who have always had to think about the interplay between intellectual and physical responses to their work, may play a more pivotal role in the development of VR than technologists, who may be content with the computers as a medium that exclusively addresses the disembodied human intellect". Jaron Lanier, who coined the term virtual reality, has always been a computer scientist who can look 
beyond technology. Lanier provided 52 definitions of VR in Dawn of the New Everything (2017). Among these definitions, two are quite striking:

First VR Definition: A twenty-first-century art form that will weave together the three great twentiethcentury arts: cinema, jazz, and programming (Lanier, 2017: 3).

Forty-third VR Definition: A new art form that must escape the clutches of gaming, cinema, traditional software, New Economy power structures, and maybe even the ideas of its pioneers (Lanier, 2017: 237).

In Lanier's words (2017), VR as "a new art form" means or should mean more than technology for artists. Artists play an important role for the exploration, development, and evolution of the potential of Virtual Reality as a developing field.

Tina Sauerlaender, one of the leading VR Artwork curators, criticizes the perception of VR as just an entertainment tool and says that accepting VR Artwork only as a movie, game or edutainment is a misconception (URL-1). VR is a new medium for the general audience, and therefore, the general audience perceives VR just as the commercial groups are marketing it. Also, according to Marshall McLuhan "people using a new medium have a difficult time breaking out of the thinking involved with the previous ones" (Transcribed by Bailenson, 2018). Nevertheless, artists have a natural gift to think outside of the box, different from the general audience. They can understand VR more conceptually. As Sauerlaender also describes it, "Visual artists are usually interested in a reflection of societal or cultural conditions or they explore the possibilities and limits their medium has to offer" (URL-1).

The fact that VR provides the user the opportunity to participate in the experience, to interact with the content, and to manipulate it has caused the traditional artist-viewer roles of the art medium to change. The person experiencing the content is no longer just a viewer, but an active participant. In addition, the fact that VR is more effective than any other medium in conveying emotions and creating a sense of empathy may provide a stronger connection between the artist and the participant. The fact that the physical world is completely blocked inside virtual reality enables the virtual environment to immerse the user and connects the user to the content with its multi-sensory features. At this point, the quality of the content presented to the user is the most important factor in terms of the VR experience. This content may be 360-degree video, a realistically modeled virtual environment, a completely abstract experience, or a combination of all these. The capabilities of VR to simulate experiences that are impossible in the physical world also provide a unique opportunity for artworks.

3D modeling programs (Maya, 3D Max, etc.) and game engines (Unity, Unreal Engine) are used on the computer to create VR content, and coding is also performed in certain processes. In other words, a significant part of the VR content production process takes place on a 2-dimensional computer screen. However, it is also possible to perform drawing, painting, animating, 3D modeling and sculpting in the virtual environment with easy and practical VR apps. One of the important reasons for the wider use of VR among artists and designers in recent years is the increase in Creative VR Apps (Tilt Brush, Medium, Quill, Gravity Sketch, etc.) used in virtual environment. The opportunity to create content using artistic tools in an unlimited virtual environment provides an immersive VR experience not only for artists and designers, but for all kinds of users. From the user perspective, drawing, painting or modelling through 6 Degrees of Freedom (6-DoF) in VR is much more comfortable and easier than constantly looking at a 2D computer screen. Because this is what is natural for human beings. Apart from its ease-use feature, Creative VR apps are also satisfying in terms of tool diversity. These apps require a 6-DoF VR Headset such as HTC Vive, Oculus Rift S/Quest, and Valve Index. There are Creative VR Apps that are also used through Windows Mixed Reality and PlayStation VR, more restrictively though.

It is possible to export artwork created in VR applications in various formats (.Fbx, .Obj, .Glb, Alembic, etc.). In addition, Unity SDKs are required to import the artworks into the Unity game engine. Some applications enable artworks to be exported as 360-degree video/photo. Considering that even the oldest of these applications was launched 5 years ago, it can be understood how new they are. As Applications and VR hardware develop, more comprehensive features will be able to be provided to users. Currently, there is still a dependence on 2D computer environments to develop comprehensive VR experiences. 


\section{IMMERSIVE EXPERIMENTAL TYPOGRAPHY IN VR ART}

In order to define experimental typography, the term typography must first be explained. Typography is the design of letters in a certain rule, order, and harmony. Typography is a repeatable system that can combine in endless ways and refers to the arrangement of letters in composition rather than their design. In other words, typography is about how letters all together look to the eye in a system. According to Ambrosse and Harris (2005: 6), "Typography is the means by which a written idea is given a visual form. It can produce a neutral effect or rouse the passions, it can symbolise artistic, political or philosophical movements, or it can express the personality of an individual or organisation".

At this point, the terms calligraphy and lettering should also be explained as they are included in the VR Artworks examined within the scope of this study. Calligraphy is defined as the art of beautiful writing in almost every resource. Calligraphy is an art based on certain rules and principles that vary from culture to culture. In terms of application, the purpose of it is to provide an aesthetic and elegant expression to the writing. But calligraphy is not just beautiful writing. It is considered a value with philosophical depth and spiritual aspect in most cultures. Traditional calligraphy is performed on paper with ink, brush, and pen (reed, bamboo, wood, metal). It is also performed on different surfaces using more diverse materials in modern interpretations.

Lettering is based on creating an original and unique composition, hand-made or through digital programs, rather than creating a system where letters can be reunited with different combinations. Unlike calligraphy, lettering is the art of drawing letters. "Calligraphy is based on penmanship; it's essentially writing letters. Lettering, on the other hand, is based on draftsmanship, i.e., drawing letters" (URL-2). Typography, calligraphy, and lettering have the power to influence the emotions of the reader/user and shape their attention and perception. Therefore, they transfer ideas and information not only by a method based on reading but also by conveying visual meanings and influencing emotions. Although each of these is an art medium, they are also elements used in artworks. The letters are both a phonetically readable representation of a text and a visual representation of a thought. In this respect, they provide a visual meaning to the meaning of the text; a meaning that words cannot express.

The use of writing in VR for artistic purposes can be considered as a new type of relationship between VR and language. It provides a new relationship experience between a user and text in the virtual environment. Considering applied studies using the writing as a core element of the VR experience Screen: Bodily interaction with text in immersive VR (Carroll et al., 2003) and Cave Writing: Toward a platform for literary immersive VR (Becker et al., 2005) can be listed as important early examples. In Carroll's Screen project, a new kind of reading experience consisting of the interaction of body and text was created in the virtual environment. Becker's Cave Writing project, on the other hand, is a research conducted with interdisciplinary student groups on the next-generation literary experiences in the virtual environment.

Writing-based VR Artworks are similar to the linguistic approach of conceptual art in a way. Since concept and thought are desired to stand out in conceptual art, the artistic production method mostly consists of formal texts. Conceptual art is defined as "post-object art or art-as-idea, artwork whose medium is an idea or a concept" (URL-3). In this respect, it is commonly believed that the basis of conceptual art is a textual content, it does not need an object, and is not related to formal appearance. Using the language in the context of conceptual art, the artists presented their works in writing. Although the use of writing in artworks dates back to much older times, conceptual artists were the first to provide words with a key role. The texts have an imaginative value in the artworks of artists such as Joseph Kosuth, Fiona Banner, and Jenny Holzer (neo-conceptual artists) who use linguistic analysis in their conceptual artworks. Regardless of whether the text is readable or not, the conceptual context is reflected by the visual impact of the writing. It is not appropriate to evaluate all VR Artworks based on writing within the scope of conceptual art. However, the ideal thing is that the artworks should have a strong conceptual aspect regardless of the medium.

It is very difficult for the text to provide easy reading for writing-based VR Artworks. Users have an non-restricted freedom in VR. Every time the users change their angle of viewing, they will see the forms of the letters from a different perspective. "Since it is not always possible to guarantee the angle of the view relative to the angle of the text, one cannot be certain of maintaining the integrity of the 
letterform" (Small, 1999: 34). Since it is not preferred to show the content to the user from a fixed point as it is in 2D environment or to restrict the user's viewing angle and mobility, which conflicts with the existence of VR; one should not expect a perfect result in terms of readability. This opinion does not include interface designs and menus that provide navigation in VR, as those are beyond the scope of this study. The writing-based VR Artworks (mostly) cannot provide an ideal environment for reading. Reading will be even more difficult, especially in animated and interactive experiences that contain intense use of letters. On the other hand, reading of such projects is not the primary purpose anyway. Conceptual and intellectual context should be able to be provided together with the holistic structure of the immersive experience. With elements such as VR experience, typographic fiction, movement, sound and interaction, the conceptual discourse of the artwork should be provided for the user experience. Therefore, in VR Artworks, instead of transferring the readability feature of typography in 2D environments to 3D virtual environments, a better choice would be to focus on exploring the new aspects that VR provides for the users. From this point of view, text-based VR Artworks can also be evaluated as experimental typography works.

Experimental typography is a practical approach based on exploration and interpretation, which is different from the traditional patterns. All kinds of materials and techniques can be used, letter forms can be distorted and even abstracted. The purpose here is to provide concept-based solutions that focus on creativity, not functionality. Experimental typography works seek new forms of visual expression and finding an original language of expression without prioritizing legibility and readability principles. From this point of view, if the visual concept of VR artworks is based on typography, calligraphy, or lettering, it can be said that the result will be experimental typography. Although typography, calligraphy, and lettering express different things terminologically, they reflect the characteristic of experimental typography when there is a purpose of artistic use in the virtual environment. There are two reasons for this situation. The first reason is that typography, calligraphy, and lettering cannot fully meet the definitions, features, rules, and principles attributed to them when they are used with VR technology in artistic contexts. The second reason is that if typography, calligraphy, or lettering are used as the main narrative element in VR Artwork, whether they are readable or not, they become visual images. It should also be noted that this interpretation does not include the use of typography, calligraphy, and lettering in the VR interfaces and menus. They can only be considered experimental typography works in line with their use as the main narrative element in VR Artworks.

Three VR Artworks have been analyzed within the scope of this article. Chalkroom (2017) by Laurie Anderson and Hsin-Chien Huang, Code of Silence by the author and The Spirit of Autobiography by NPM and HTC VIVE have been analyzed in terms of their use of experimental typography in VR Art.

\section{Chalkroom}

Chalkroom a.k.a. La Camera Insabbiata (2017), the Best VR Experience Award winner at the 74th Venice Film Festival, is an interactive VR Art installation co-created by Laurie Anderson and HsinChien Huang. Consisting of eight different rooms that the user can fly and explore in the virtual world, this VR artwork consists of handwritten text and drawings written with white chalk on huge chalkboards representing memories. Once the user is inside the VR, he/she moves towards the center of the Chalkroom, moves along a dark corridor covered with handwriting and drawings on the walls, accompanied by Laurie Anderson's audio narration. As the beginning of the immersive story, this section prepares the user for the VR experience. After the arrival at the center, the user can freely fly among the rooms that provide different contents and can freely explore them. The names of these eight rooms that provide different themes are as follows: The Cloud Room, The Dog Room, The Sound Room, The Writing Room, The Anagram Room, The Water Room, The Dance Room and The Tree Room (Figure 1). 


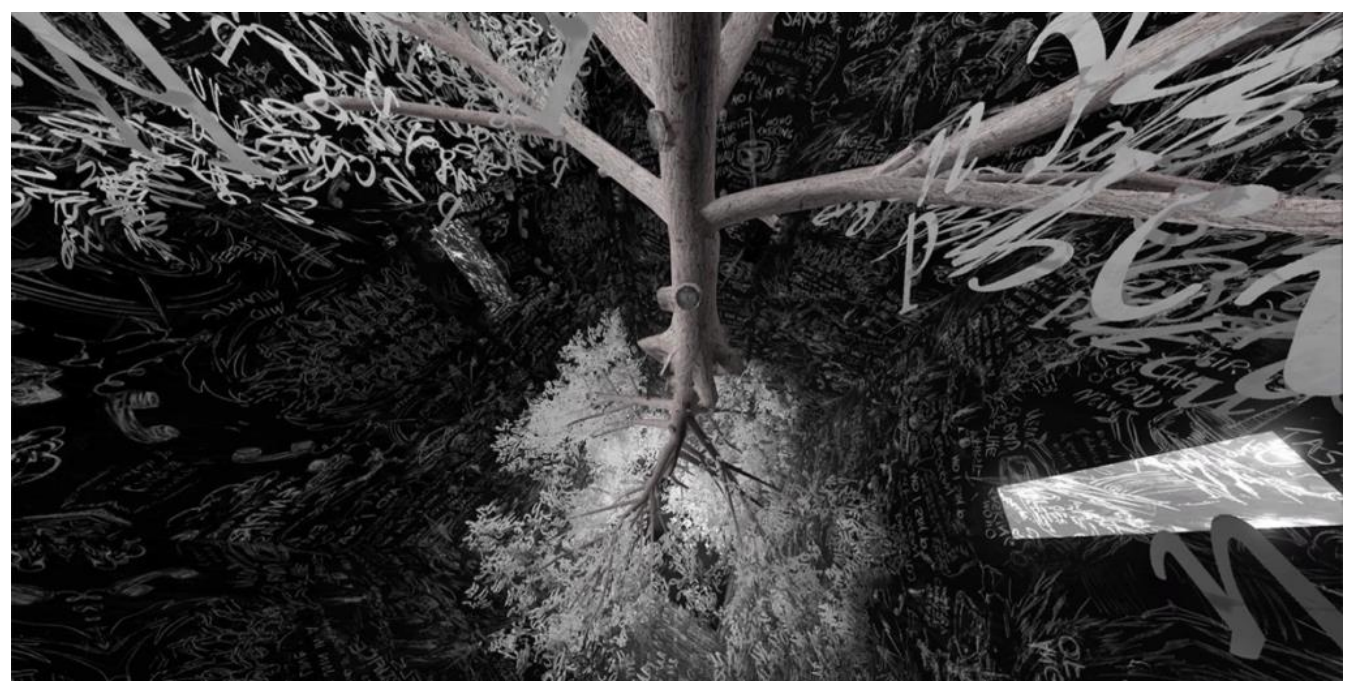

Figure 1. Chalkroom by Laurie Anderson and Hsin-Chien Huang, The Tree Room, 2017. Source: URL-4

The virtual environment decorated with images, symbols, and handwriting creates an uneasy sense of curiosity and gives a feeling of being lost in the dark labyrinths of the mind. In the Cloud Room, the user can interact with the nebula vortex of words. The user can perform sculpting with his/her own voice in the Sound Room and can fly around the tree made of letters in the Tree Room. As the user navigates through mazes of huge chalkboards, they get involved in the story by experiencing different forms of interaction in each room. The fragmented words may create new meanings by reconstructing of them with user interaction.

While navigating through the Chalkroom, the user will perceive the visual effect of the texts and drawings as a whole and will randomly read the texts that attract his/her attention. In this respect, Chalkroom provides limitless exploration variations, and enables each user to have a unique experience. As Laurie Anderson (URL-5) stated, Chalkroom "is a library of stories, and no one will find them all". Scribble writing and sketches on chalkboards resemble notes kept by the stream of consciousness method. This is quite the opposite of legibility and readability principles of typography, traditional basic composition arrangement and clean design solutions. The free and intuitive understanding of the writing is similar to the anomaly characteristic of experimental typography. The irregularity of the texts, the marks of the wooden eraser, the letters flying around, the dusty and dirty surfaces present an atmosphere different from the usual VR experiences. The carefully crafted colorful 3D modelling seen in most VR apps offer a dark world filled with sketches and imperfect handwriting instead of bright, clear, and beautiful landscapes (Figure 2). 


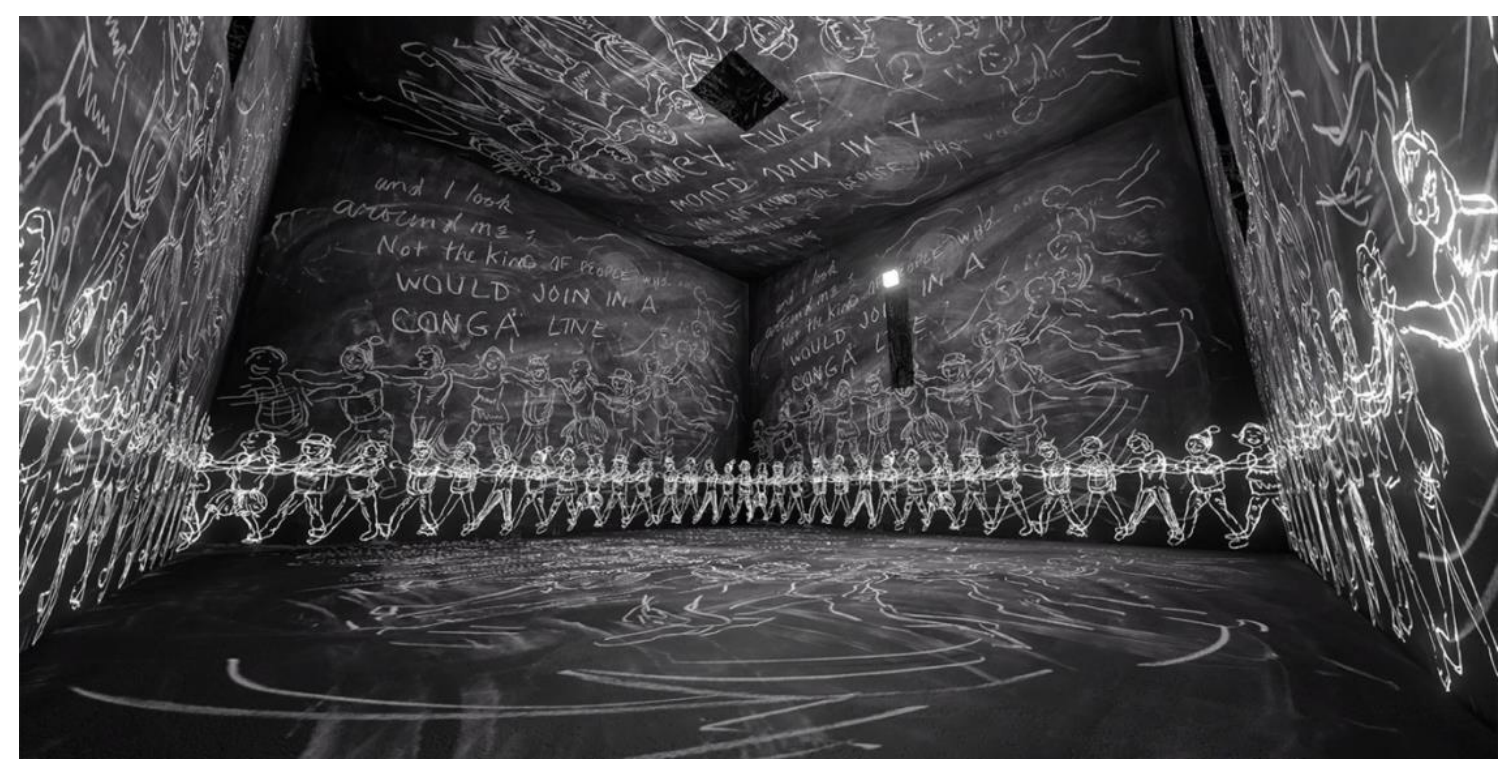

Figure 2. Chalkroom by Laurie Anderson and Hsin-Chien Huang, The Dance Room, 2017.

Source: URL-6

Anderson, who has also created artworks on music, film and sculpture throughout her art life, stated that she always tried to generate the experience of "being completely disembodied" in all of her works. In her own words, VR means: "Virtual reality does what I've always wanted to do as an artist from the time I've started, which is a kind of disembodiment" (URL-7). Chalkbaord successfully combines the conceptual and intellectual context with the opportunities provided by VR. It is an experience that expands perception in the context of body, being, mind, language and narrative. Chalkbaord not only demonstrates the unique possibilities the VR environment can offer for the narration of immersive stories with experimental typography, but also demonstrates the different uses of VR in contrast to conventional practices.

\section{Code of Silence}

Very few studies have been carried out on writing-based VR Artworks. Although the use of VR as an art medium dates back to the 1990s, there are very few artworks in which writing plays a central role as a visual element. In the literature, the number of studies on the use of writing in VR Artworks is quite limited. Therefore, an individual project named Code of Silence (2020) was carried out in order to create a writing-based VR Artwork and explore the potential of VR in terms of experimental typography. As a result, each stage of the process could be experienced personally. The Code of Silence was created with the Oculus Rift S Headset in Tilt Brush, VR painting application, and later environmental elements were added through the Unity game engine to develop a VR experience in which users can navigate. Users can navigate in a virtual environment with the teleport feature. The 360-degree video of Code of Silence can also be viewed with 3-DoF (3 Degrees of Freedom) VR headsets such as Google Cardboard, Samsung Gear VR, and Google Daydream.

Code of Silence consists of red spheres of various sizes waiting to be discovered in an environment of vast dark black sea and gloomy sky. The spheres are intended as a personal library of memories, and each sphere functions as a storage for memories of a different person. Memories are recorded by writing on the inner walls of the spheres. Users can navigate in the virtual environment with the teleport feature and enter into the huge sphere in the center (Figure 3). 


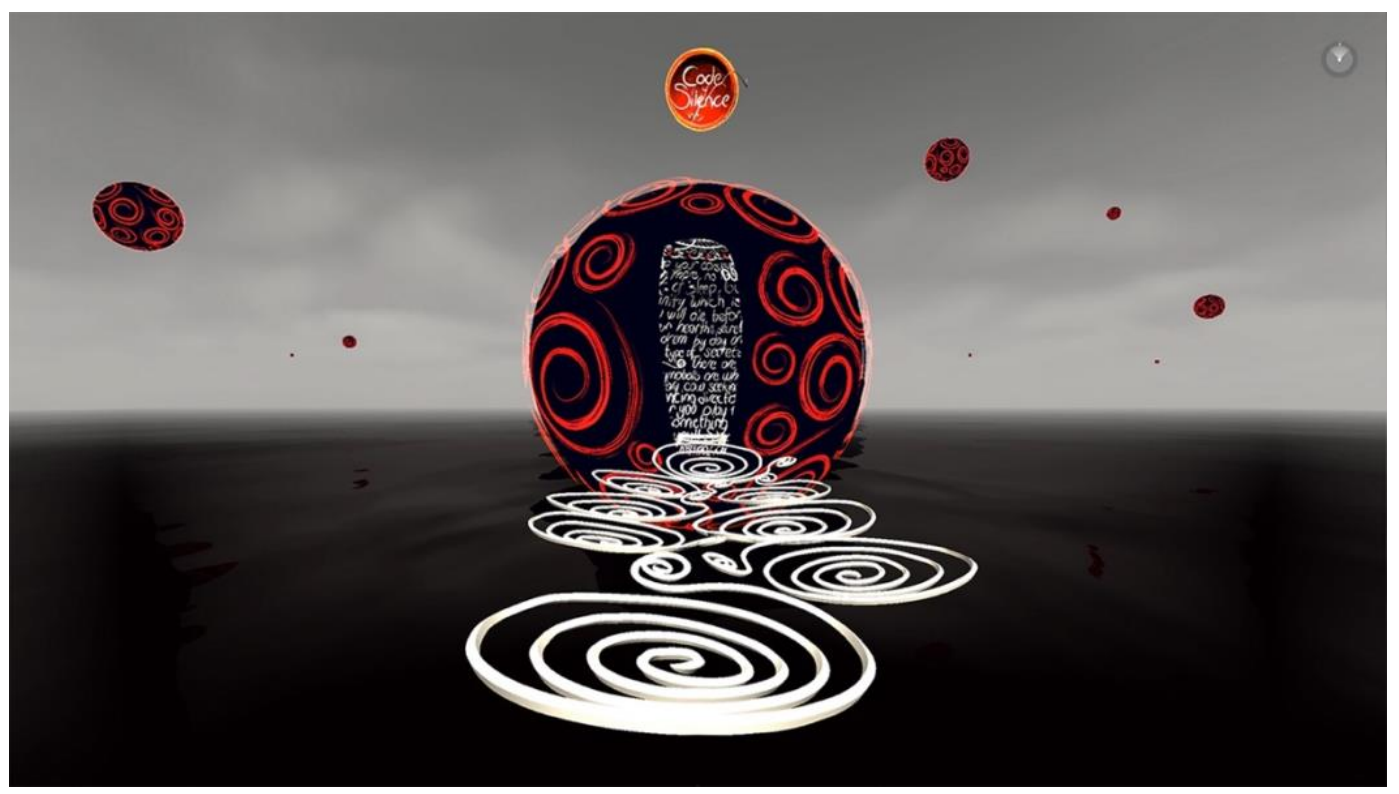

Figure 3. Code of Silence by author, 2020.

The texts inside this sphere are quoted from Haruki Murakami's novel Kafka on the Shore (2002). The inner wall of this sphere is completely covered with handwritten texts. The texts are written with the 3D Brushes of the Tilt Brush App. There is also a lettering design inside the upper hemisphere of the big sphere. For the lettering, a 3D composition was created by carefully drawing each letter. Although writing in the space is a different action from usual habits, Tilt Brush App offers a comfortable and smooth writing experience. For this project, before I started working inside VR, I developed my ideas and concepts by drawing 2D sketches. Then I started drawing in VR in light of the final draft. But while working on my task, the endless freedom of drawing in a VR environment led me to modify my idea in reference draft. Although the main concept of Code of Silence and the intellectual aspect of it did not change, I personally experienced the potential of VR to change perception and interpretation in the creation processes (Figure 4).

Animative brushes were used in certain places outside and inside the spheres. The motifs on the floor and ceiling of the inner surface of the sphere were animated with animative brushes that provide the effect of flame. After the sphere was completed with Tilt Brush, it was imported into the Unity game engine. Dark black sea moving with calm waves and gloomy sky were added via Unity. In addition, a deep dark ambient music was added for the users to experience the unease feeling at high levels. The aim here is to trigger emotions and immerse the user in artwork completely and enable user to experience the feeling of presence at the highest level. The main purpose of these environmental elements added via Unity was to support the content of the text inside the spheres. Because it might be difficult to read the entire handwriting texts on the inner walls of the sphere. Although the handwriting is readable to a certain extent, the text continues as uninterrupted spirals through the sphere. On the other hand, the important thing in this project is that the writing turns into an image, and therefore, leaves a visual effect. VR provides an endless exploration area for experimental typography. In this respect, the potential of VR in terms of experimental typography is not limited to the technological opportunities only. It also supports the intuitive and conceptual approach of experimental typography with its features of interaction, immersion, and presence. 

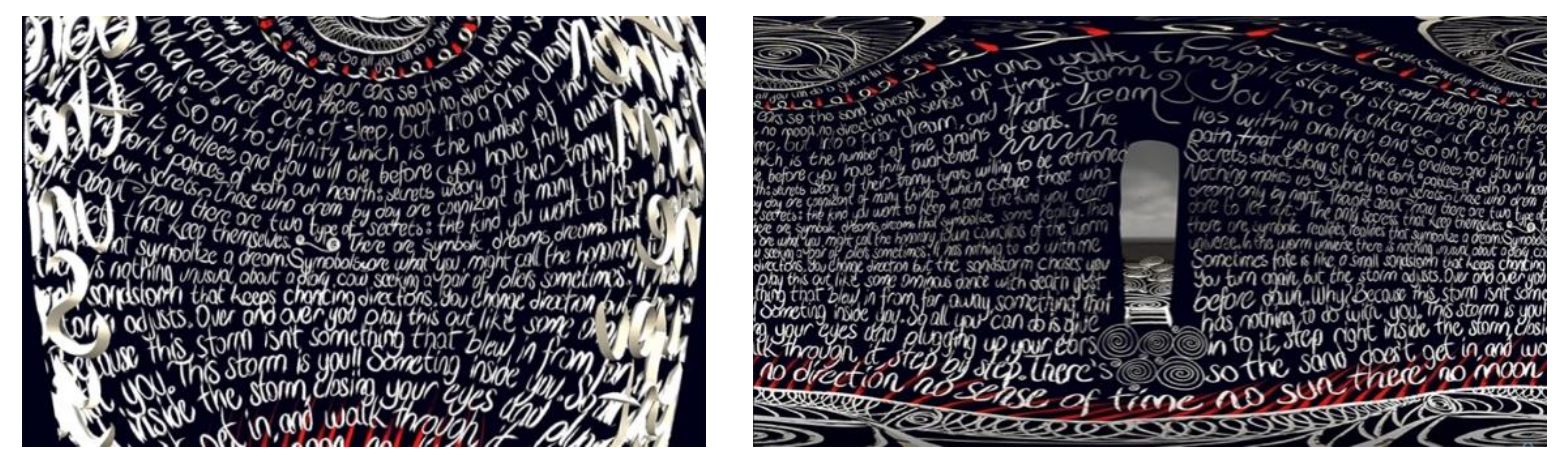

Figure 4. Code of Silence by author, 2020.

\section{The Spirit of Autobiography}

The Spirit of Autobiography (2017), co-developed by Taiwan's National Palace Museum (NPM) and HTC VIVE, is described as the world's first VR calligraphy installation. It was inspired from Autobiography, the world-famous wild cursive script masterpiece by Tang dynasty monk Huaisu. Wild cursive script is described as a free and endless style that includes smooth contours, bold character combinations, and elegant circular movements. Master calligrapher Huaisu's Autobiography is dated back to $777 \mathrm{AD}$, and its original dimensions are $28.3 \mathrm{~cm}$ by $755 \mathrm{~cm}$ (Figure 5).
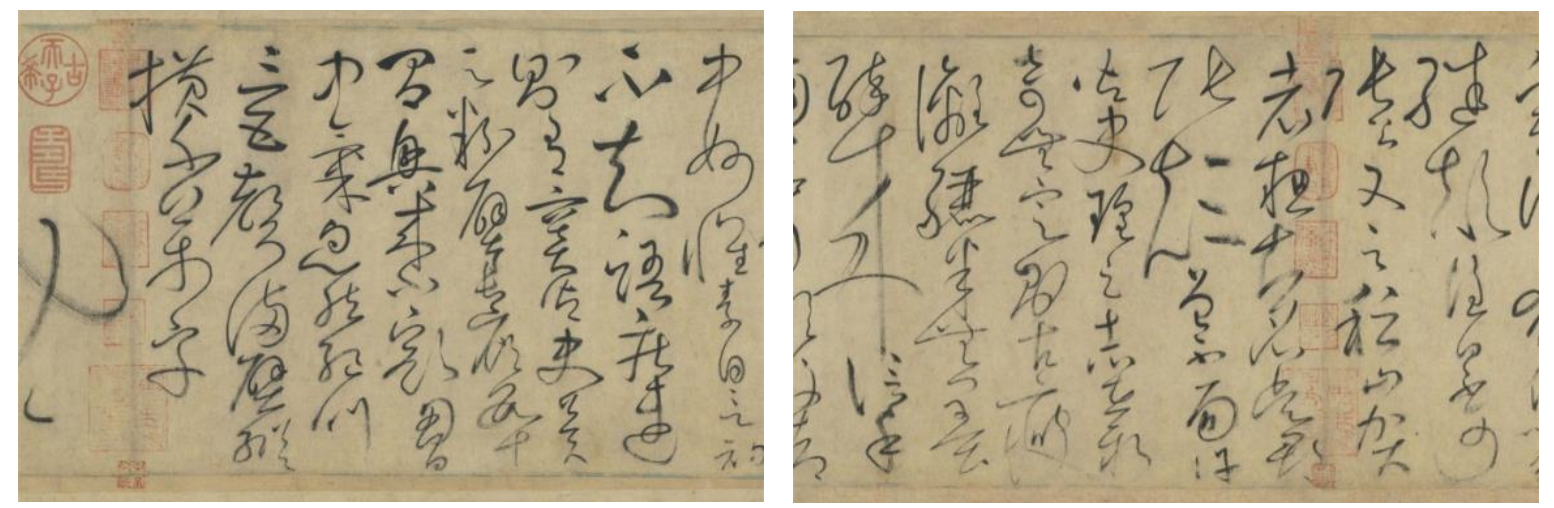

Figure 5. Autobiography by Huaisu (fragment), handscroll, ink on paper, $28.3 \times 755 \mathrm{~cm}, 777$.

Source: URL-8

Huaisu's Autobiography consists of poetic tributes to his calligraphy works by his contemporaries. While some lines refer to natural phenomena, in certain passages there is a narrative of Huaisu's being the heir to the wild and crazy cursive script of Chang Hsu, who pursued unconventional and unstoppable qualities. "The entire work was done with fine yet strong brushwork, the features continuous throughout for an unlimited range of unusual expressions, making this a masterpiece of cursive script" (URL-9). The most famous passage includes the following statement: "My brush varies as the snake glides poised into his post, or thrashes in tune with the windstorm upon the walls" (URL-9). The narrative in the VR experience reflects the speed, rhythm, and independent nature of the depiction and wild cursive script in this famous passage. The calligraphy was placed 360-degrees allowing immersion of the user in VR. Calligraphy transforms into snakes and dragons, floating in the virtual environment with smooth movements, while dancers transform the fluidity of brush movements into dance forms (Figure 6). In another scene, the calligraphy works slowly come out of the ink dripping into the water and fly towards the sky. Finally, users can join this experience by practicing calligraphy writing with their virtual brush. 


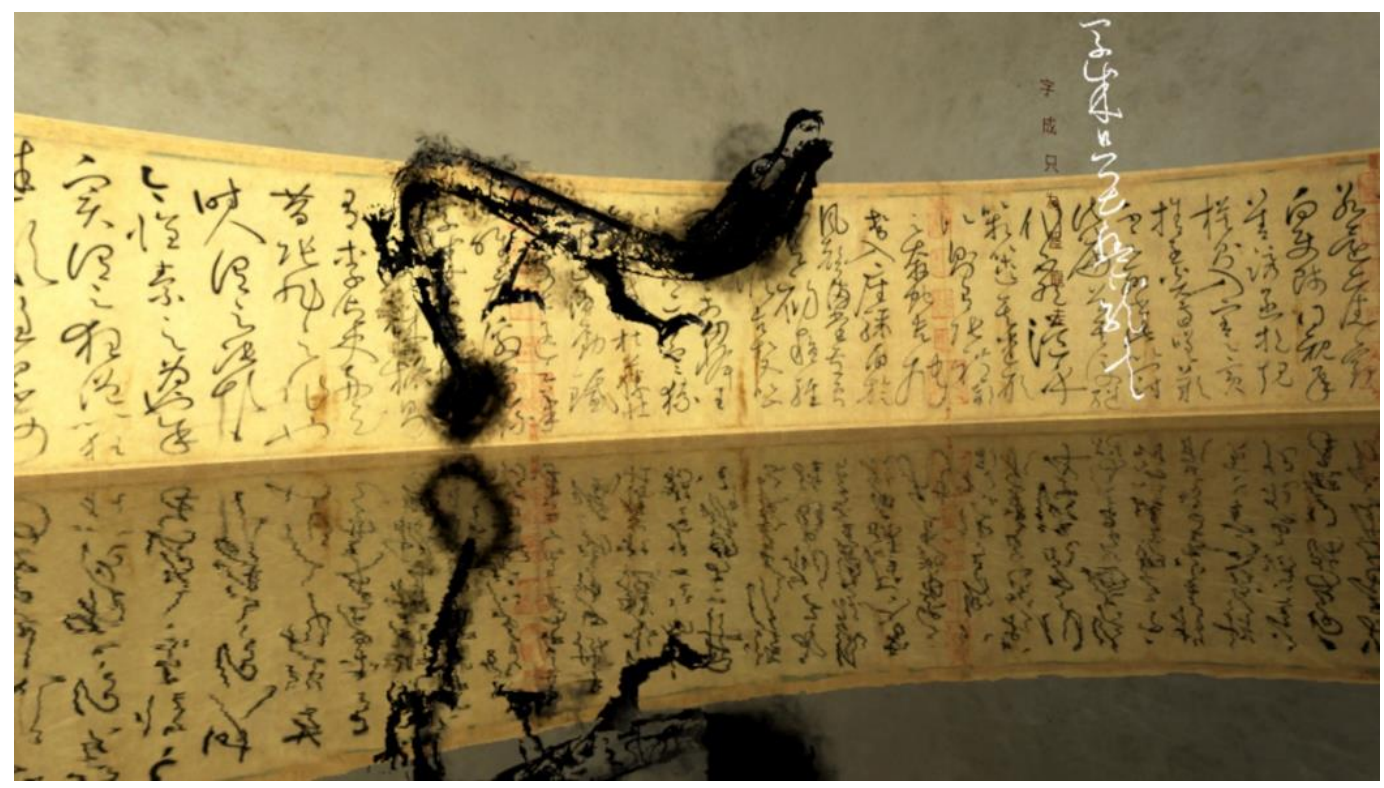

Figure 6. Spirit of Autobiography by Taiwan's NPM and HTC VIVE, 2017. Source: URL-10

Autobiography consists of poetic tributes to his calligraphy works by his contemporaries. While Calligraphy also has a philosophical aspect. It is an ancient art of discipline, mind and spirituality. In this sense, VR is the most effective medium to make a person feel the philosophical depth of calligraphy and reflect its conceptual infrastructure with immersive narratives. The Spirit of Autobiography VR installation effectively reflects the smooth and rhythmic nature of the text, with Huaisu's wild and crazy brushwork.

\section{CONCLUSIONS}

Although the use of virtual reality as an art medium dates back to the 1990s, only a limited number of projects were able to be carried out due to the high cost of VR equipment and due to the lack of a widespread sales network. The introduction of VR Headsets for individual use as of 2016 enabled more VR Artworks to be generated. The immersion, presence and interaction feature of VR provide artists with unique possibilities and inspire them to discover new methods and interpretation styles. The relationship between art and VR can enable development, evolution and expansion for both directions. The role of art in the exploration of opportunities that VR may provide has also been emphasized by the predecessors of VR. Against the perception of VR as an entertainment tool, artists will/should be the ones to deal with the subject in a more intellectual context. The VR Artworks Chalkroom, Code of Silence and The Spirit of Autobiography, which are examined within the scope of this article, provide the user with the conceptual discourse and intellectual aspect of the works with elements such as typographic fiction, movement, sound and interaction. In this sense, the fictional structure of the content and the effective use of multi-sensory features are significant in order to provide an immersive experience to the users.

VR is perceived as a platform with the potential to change the artwork generation methods and consumption paradigms. The increase in artworks generated with creative Creative VR apps that enable drawing, painting, animating, 3D modeling and sculpting in the virtual environment can be considered as the beginning of this change. We are in an age in which the possibilities and potential of VR are still being discovered for both content producers and users. The way art uses VR, how it interprets it, and the change VR will cause in art will expand the perspective for both. In this respect, VR Artworks, the content of which is created by using writing, may play a role in the exploration of not only the technological capabilities of VR, but also its conceptual and intellectual aspects. 
Writing is the most important invention of human history. It enables meaningful signs that come together systematically to establish a visual-based communication among people. Moreover, writing is a tool that has the power to convey memories, information and ideas through time and space. The most effective use of writing in both a linguistic context and as a visual expression has been within the scope of conceptual art. This situation has brought new discourses and perspectives to the art. In this context, the inclusion of VR in the combination of writing and art may provide completely different results in conceptual and intellectual contexts. The intersection of writing, art and VR has a rich potential for different perspectives and new patterns.

Using typography, calligraphy, and lettering in VR technology for artistic purposes can be considered as an experimental approach. When typography, calligraphy, and lettering entered the virtual environment for artistic purposes, through the characteristic of VR technology and the course of the immersive narrative, they transform into visual forms of expression, which changes current definition. In this regard, they can be considered as experimental typography works if they are to be used as the main narrative element in VR Artworks. Experimental typography is a practice based on exploration and interpretation, seeking new forms of visual expression apart from traditional patterns. It attempts to find an original language. VR Artworks based on experimental typography may reveal various contents that explore the role of language for art as structured images in virtual environment. In addition, the use of experimental typography in these VR Artworks can expand the narrative language of VR by providing different results from the formal approach in traditional VR experiences that are known for their intense use of writing. In this respect, the potential of VR in terms of experimental typography is not limited to the technological opportunities only. It also supports the intuitive and conceptual approach of experimental typography with its features of interaction, immersion, and presence. The use of experimental typography still having few examples in terms of VR Artworks is an issue that needs to be studied more both practically and theoretically.

\section{REFERENCES}

Ambrose, G. and Harris, P. (2015). Typography. Lausanne, Switzerland: AVA Publishing SA.

Bailenson, J. (2018). Experience on demand. New York, NY: W. W. Norton \& Company.

Baños, R. M., Botella, C., Alcañiz, M., Liaño, V., Guerrero, B. and Rey, B. (2004). Immersion and emotion: their impact on the sense of presence. Cyberpsychology \& Behavior, 7(6), 734-741. doi:10.1089/cpb.2004.7.734

Biocca, F. and Levy, M. R. (1995). Communication applications of virtual reality. In F. Biocca \& M. R. Levy (Eds.), Communication in the age of virtual reality (pp. 127-157). Hillsdale, NJ: Lawrence Erlbaum Associates Inc.

Bryson, S. (2013). Virtual Reality: A Definition History - A Personal Essay. Retrieved March 15, 2021, from https://arxiv.org/pdf/1312.4322.pdf

Chirico, A., Ferrise, F., Cordella, L. and Gaggioli, A. (2018). Designing awe in virtual reality: an experimental study. Frontiers in Psychology, 8, 1-14. doi:10.3389/fpsyg.2017.02351

Cruz-Neira, C. (1993). Virtual reality overview. ACM SIGGRAPH'93 Course Notes 23, 1-18.

Diemer, J., Alpers, G.W., Peperkorn, H.M., Shiban, Y. and Mühlberger, A. (2015). The impact of perception and presence on emotional reactions: a review of research in virtual reality. Frontiers in Psychology, 6(26), 1-9. doi:10.3389/fpsyg.2015.00026

Freeman, J., Lessiter, J., Pugh, K. and Keogh, E. (2005). When presence and emotion are related, and when they are not. In Proceedings of the Conference at Presence 2005. London, England. Retrieved March 11, 2021, from https://www.researchgate.net/publication/228744500_When_ Presence_and_emotion_are_related_and_when_they_are_not

Gigante, M. A. (1993). Virtual reality: definitions, history and applications. In R. A. Earnshaw, M. A. Gigante \& H. Jones (Eds.), Virtual Reality Systems (pp. 3-14). London, England: Academic Press. 
Gobira, P. and Mozelli, A. (2018). Expansion of uses and applications of virtual reality. In Information Resources Management Association (Ed.), Virtual and Augmented Reality: Concepts, Methodologies, Tools, and Applications (pp. 1-17). Hershey, PA: IGI Global. doi: 10.4018/978-1-5225-5469-1.ch001

Kelley, B. and Tornatzky, C. (2019). The artistic approach to virtual reality. In Proceedings of VRCAI'19: The 17th International Conference on Virtual-Reality Continuum and its Applications in Industry (pp. 1-5). New York, NY: Association for Computing Machinery. doi:10.1145/3359997.3365701

Lanier, J. (2017). Dawn of the new everything: encounters with reality and virtual reality. New York, NY: Henry Holt and Company.

Laurel, B. (1995). Virtual Reality. Scientific American, 273(3), 90-90. Retrieved March 8, 2021, from http://www.jstor.org/stable/24981732

McMahan, A. (2003). Immersion, engagement and presence: A Method for Analyzing 3D Video Games. In M.J.P. Wolf \& B. Perron (Eds.), The Video Game Theory Reader (pp. 67-86). New York, NY: Routledge.

Mütterlein, J. (2018). The three pillars of virtual reality? Investigating the roles of immersion, presence, and interactivity. In Proceedings of the 51st Hawaii International Conference on System Sciences (pp. 1407-1415). doi: 10.24251/HICSS.2018.174

Raz, G. (2019). Virtual reality as an emerging art medium and its immersive affordances. In N. Carroll, L.T. Di Summa \& S. Loht (Eds.), The Palgrave Handbook of the Philosophy of Film and Motion Pictures (pp. 995-1014). Cham, Switzerland: Palgrave Macmillan. doi: 10.1007/978-3-030-19601-1_42

Slater, M., Linakis, V., Usoh, M. and Kooper, R. (1996). Immersion, presence and performance in virtual environments: an experiment with tri-dimensional chess. In Proceedings of VRST '96: ACM Symposium on Virtual Reality Software and Technology (pp. 163-172). New York, NY: Association for Computing Machinery. doi: 10.1145/3304181.3304216

Small, D. L. (1999). Rethinking the Book. (PhD Thesis. Massachusetts Institute of Technology, Media Arts and Sciences, Cambridge, MA). Retrieved February 29, 2021, from http://hdl.handle.net/1721.1/29143

Visch, V. T., Tan, E. S., and Molenaar, D. (2010). The emotional and cognitive effect of immersion in film viewing. Cognition and Emotion, 24(8), 1439-1445. doi:10.1080/02699930903498186

\section{ELECTRONIC SOURCES}

URL-1: Rabimov, S. (2020). Tina Sauerlaender interview. Why first virtual reality art prize is perfect for 2020. Forbes. https://www.forbes.com/sites/stephanrabimov/2020/11/27/why-first-virtual-realityart-prize-is-perfect-for-2020/?sh=6dac4d0d2027 Date of Access: 11.03.2021

URL-2: Alessio, J. (2013). Understanding the difference between type and lettering. Smashing Magazine https://www.smashingmagazine.com/2013/01/understanding-difference-between-type-andlettering/ Date of Access: 02.03.2021

URL-3: Wainwright, L. S. (2018). Conceptual art. Encyclopedia Britannica. https://www.britannica.com/art/conceptual-art Date of Access: 24.04.2021

URL-4: Chalkroom by Laurie Anderson \& Hsin-Chien Huang, The Tree Room. www.storynest.com/pix/_4proj/i_laCameraInsabbiata/p0.php?lang Date of Access: 04.04.2021

URL-5: Anderson, L. (2017) Interview: A Virtual Reality of Stories [Video file]. Louisiana Channel. https://www.youtube.com/watch?v=zHT016FbR30 Date of Access: 30.04.2021

URL-6: Chalkroom by Laurie Anderson \& Hsin-Chien Huang, The Dance Room. www.storynest.com/pix/_4proj/i_laCameraInsabbiata/p0.php?lang Date of Access: 04.04.2021 
URL-7: Sheets, H. M. (2017). Laurie Anderson interview. A Museum Where Giant Art Has Room to Breathe. The New York Times. https://www.nytimes.com/2017/05/26/arts/design/mass-moca-newbuilding.html Date of Access: 11.03.2021

URL-8: Autobiography by Huaisu (fragment), handscroll, ink on paper, 28.3 x $755 \mathrm{~cm}, 777$. http://theme.npm.edu.tw/exh108/NPMxKMFA/en/page-4.html Date of Access: 16.04.2021

URL-9: NPM - National Palace Museum. (2019). Euphoria of Sight and Spirit. NPM x KMFA: New Horizons-New Media Art Exhibition. https://theme.npm.edu.tw/exh108/NPMxKMFA/en/page-4.html Date of Access: 30.04.2021

URL-10. The Spirit of Autobiography by Taiwan's National Palace Museum and HTC VIVE. http://theme.npm.edu.tw/exh108/NPMxKMFA/en/page-4.html Date of Access: 16.04.2021

Atıf İçin: Uyan Dur, B. İ. (2021) Sanal Gerçeklik Sanatı ve Sürükleyici Deneysel Tipografi, Yeni Medya Elektronik Dergisi, 5 (3), 219-233 